\title{
Soluble Fas may be a proinflammatory marker after cardiopulmonary bypass in children
}

U. Joashi, MRCPa

S. M. Tibby, MRCPa

C. Turner, $\mathrm{BSc}^{\mathrm{a}}$

A. Mayer, MRCPa

C. Austin, FRCS

D. Anderson, FRCS ${ }^{b}$

A. Durward, FCPa

I. A. Murdoch, FRCPa
From the Departments of Pediatric Intensive Care $^{\mathrm{a}}$ and Pediatric Cardiothoracic Surgery, Guy's Hospital, London, United Kingdom.

Received for publication May 11, 2001; revisions requested June 15, 2001; revisions received July 3, 2001; accepted for publication July 10, 2001

Address for reprints: Shane Tibby, MRCP, Department of Pediatric Intensive Care, Guy's Hospital, Saint Thomas Street, London SE1 9RT, United Kingdom (E-mail: Shane.Tibby@gstt.sthames.nhs.uk).

J Thorac Cardiovasc Surg 2002;123:137-44

Copyright (C) 2002 by The American Association for Thoracic Surgery

0022-5223/2002 $\$ 35.00+0 \quad \mathbf{1 2 / 1 / 1 1 8 6 8 5}$

doi: $10.1067 / \mathrm{mtc} .2002 .118685$
Objectives: Ischemia-reperfusion injury after cardiopulmonary bypass is known to provoke an inflammatory response, which can be attenuated with steroid pretreatment. Cardiopulmonary bypass is also known to stimulate apoptosis. Induction of the cellular apoptotic cascade occurs via interaction between two membrane receptors: Fas and Fas ligand. Both molecules also exist in soluble forms, whose significance remains undetermined; however, both may have a proinflammatory role. We aimed to document the temporal profile of soluble Fas and soluble Fas ligand after cardiopulmonary bypass and to investigate whether steroid pretreatment alters this response.

Methods: The study was of a nonrandomized, nonblinded, prospective nature. Twenty-seven infants were monitored prospectively, of whom 13 received dexamethasone at induction of anesthesia. Soluble Fas, soluble Fas ligand, and interleukin 6 were measured from induction of anesthesia until 24 hours after admission to the intensive care unit. Data on clinical and laboratory variables were also collected at the same time intervals.

Results: As expected, dexamethasone pretreatment attenuated interleukin 6 release and the clinical systemic inflammatory response after bypass. Soluble Fas showed a remarkably similar profile to interleukin 6 , in terms of temporal release and attenuation with steroids. There was also a correlation between maximum soluble Fas and markers of capillary leak (colloid requirement and drain loss). Conversely, soluble Fas ligand release was unchanged by cardiopulmonary bypass and steroid administration. However, patients with higher soluble Fas ligand levels exhibited a more dramatic drop and delayed recovery in monocyte count, consistent with the role of this molecule in apoptosis.

Conclusions: Release of soluble Fas and soluble Fas ligand follows a markedly different temporal profile after cardiopulmonary bypass. The similarity between soluble Fas and interleukin 6, together with the attenuation of both with steroids, may suggest a role for soluble Fas as a proinflammatory marker.

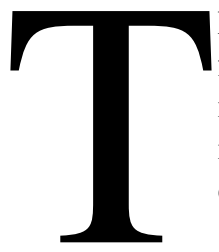

he systemic inflammatory response accompanying ischemia-reperfusion injury after cardiopulmonary bypass (CPB) is well documented. ${ }^{1}$ The mechanisms of this response include activation of inflammatory cytokine cascades, ${ }^{2}$ oxidative stress, ${ }^{3}$ and generation of reactive oxygen species. ${ }^{4}$

Another important consequence of ischemia-reperfusion injury is the triggering of apoptotic cell death ${ }^{5}$ through the Fas/Fas ligand system. ${ }^{6}$ Fas (also known as 
CD95) is a 45-kd type I membrane-associated glycoprotein of the tumor necrosis factor receptor family. ${ }^{7}$ Fas is expressed in a variety of cells, including cardiomyocytes, vascular endothelium, and cells of the immune system. Fas ligand (FasL) is a 40-kd type II membrane protein, akin to tumor necrosis factor- $\alpha$, found predominantly on activated $\mathrm{T}$ cells and natural killer cells. ${ }^{7}$ Apoptosis occurs when FasL binds to Fas, resulting in trimerization of Fas, caspase activation, and cell death. ${ }^{8}$

Both Fas and FasL also exist in soluble forms (sFas, sFasL), which can be produced de novo or from conversion of the membrane-bound form by a metalloproteinase., ${ }^{9,10}$ The importance of the membrane-bound form of these molecules in a variety of disease states is increasingly recognized, although the significance of the soluble form of Fas and FasL has yet to be fully elucidated. ${ }^{11-20}$ Ischemia-reperfusion injury akin to CPB produces myocardial sFasL release and apoptosis in animals ${ }^{6}$; whether this also happens in humans is unknown. Interestingly, membrane-bound FasL on vascular endothelium may be involved in maintenance of vascular integrity, with loss of FasL leading to capillary leak, ${ }^{21}$ a common phenomenon after CPB. If so, loss of expression of membrane-bound FasL by conversion to sFasL should result in higher sFasL levels and greater capillary leak after CPB. Soluble Fas is also found in conditions of acute and chronic inflammation. ${ }^{11-13,17-20,22-26}$ These data suggest that both sFasL and sFas may also possess proinflammatory properties, in addition to their apoptotic roles.

Proinflammatory cytokine release is attenuated by pretreatment with steroids, which has potentially beneficial clinical implications. ${ }^{27,28}$ However, what effect, if any, steroid administration may have on $\mathrm{sFas} / \mathrm{sFasL}$ release in the clinical setting is unknown.

We have conducted an observational study examining 3 issues: (1) documentation of the time course of release of sFas/sFasL after CPB, (2) whether pretreatment with dexamethasone alters this response in terms of (a) sFas/sFasL release and (b) the clinical inflammatory response with capillary leak after CPB, and (3) whether levels of either molecule relate to an indirect indicator of apoptosis as measured by the absolute monocyte count.

\section{Patients and Methods}

The study was of a prospective, observational nature. Institutional ethical approval was given, and informed consent for blood sampling was obtained from patients' parents or legal guardians before enrolment. Twenty-seven patients undergoing surgical repair of congenital heart defects were studied. Patients either were given dexamethasone (DEX; $0.25 \mathrm{mg} / \mathrm{kg})$ at induction of anesthesia $(\mathrm{n}=$ 14) or were not given DEX ( $n=13)$ according to anesthetic preference. The surgical, anesthetic, and pediatric intensive care unit (PICU) staff were unaware of the study objectives. Sample size was not calculated because the temporal profiles of sFas and sFasL were unknown.
Potential confounding variables were recorded and included the following: age, weight, sex, and duration of CPB, aortic crossclamping, and circulatory arrest. Arterial blood samples were taken and clinical variables recorded at the following time points: induction of anesthesia, immediately after cessation of CPB before protamine administration, and 1, 6, 12, and 24 hours after admission to the PICU. Interleukin 6 (IL-6) was measured in addition to sFas and sFasL. IL-6 was chosen as a typical marker of cytokine response, because the time course of release of this cytokine and its attenuation with steroid is well documented. ${ }^{27-29}$ Clinical and laboratory variables reflecting systemic inflammatory response and capillary leak in the first 24 hours are detailed below.

\section{Anesthesia}

Anesthetic induction consisted of intravenous fentanyl $(5 \mu \mathrm{g} / \mathrm{kg})$ or ketamine $(1 \mathrm{mg} / \mathrm{kg})$. Inhaled isoflurane $(0.5 \%)$ and intermittent bolus intravenous fentanyl $(10 \mu \mathrm{g} / \mathrm{kg})$ were used for maintenance. Neuromuscular blockade was achieved with bolus intravenous pancuronium $(100 \mu \mathrm{g} / \mathrm{kg})$.

\section{CPB}

Heparin $(3 \mathrm{mg} / \mathrm{kg})$ was administered before commencement of CPB to maintain activated clotting times greater than 480 seconds during bypass, and anticoagulation was reversed with protamine sulphate after discontinuation of CPB.

The extracorporeal system was non-heparin bonded and consisted of the following: roller pump (Sarns 9000; Terumo Cardiovascular Systems, Ann Arbor, Mich), oxygenator (Polystan A/S, Copenhagen, Denmark), Polystan Safe Micro (patients $<10$ $\mathrm{kg}$ ), Polystan Safe Mini (patients 10-15 kg), and Terumo Capoix SX10 (patients $>15 \mathrm{~kg}$ ). All patients received slow continuous utrafiltration while on bypass (Gambro FH 22 and 66 filters [Gambro BCT, Stockholm, Sweden] for patients $<5 \mathrm{~kg}$ and Minntech HPH 400 [Minntech Corporation, Minneapolis, Minn] for those $>5 \mathrm{~kg}$ ). Priming solution comprised packed red cells (to maintain hematocrit value $>24 \%$ on bypass), sodium bicarbonate $(8.4 \%)$ $20 \mathrm{~mL} / \mathrm{L}$ for clear primes and $1 \mathrm{~mL} / \mathrm{bag}$ of packed red cells, mannitol (20\%) $2 \mathrm{~mL} / \mathrm{kg}$ body weight, heparin $250 \mathrm{IU} / \mathrm{kg}$ body weight, Hartmann's solution in equal volumes with Haes-Steril (only with clear primes), or Haes-Steril (10\%) as the remainder of the priming volume. Patients weighing less than $7 \mathrm{~kg}$ received $50 \mathrm{~mL}$ of fresh frozen plasma in the prime, replacing the equivalent volume of clear fluid. CPB was initiated at a cardiac index of $2.6 \mathrm{~L} \cdot \mathrm{min}^{-1} \cdot \mathrm{m}^{-2}$ and maintained at this flow rate regardless of the degree of induced hypothermia. Flow was nonpulsatile, and an alpha-stat blood gas strategy was used. Warm blood cardioplegia was used in all patients.

\section{Blood Sampling}

All blood samples were taken from indwelling arterial catheters from the radial, brachial, or femoral artery. Two milliliters of blood was placed in a tube containing ethylenediaminetetraacetic acid and immediately centrifuged at $4^{\circ} \mathrm{C}$ for 10 minutes at 10,000 $\mathrm{rpm}$. Plasma was aspirated, transferred to cryovials, and stored at $-80^{\circ} \mathrm{C}$ before biochemical analysis. IL-6, sFas, and sFasL levels were measured by double sandwich enzyme-linked immunosorbent assay using a commercial kit (Bendermed Systems; Medsystems Diagnostics, Vienna, Austria). 
TABLE 1. Demographic and CPB data

\begin{tabular}{lccc}
\hline Variable & Placebo $(\mathbf{n}=14)$ & DEX $(\mathbf{n}=13)$ & $P$ value \\
\hline Age (mo) & $7.5(2.5-9.8)$ & $2.0(0.1-10.0)$ & .38 \\
Weight (kg) & $6.5(4.3-9.4)$ & $4.0(3.3-7.0)$ & .22 \\
Sex (M:F) & $11: 3$ & $7: 6$ & .24 \\
CPB (min) & $99(82-124)$ & $74(70-110)$ & .15 \\
Aortic crossclamp (min) & $65(42-74)$ & $48(45-74)$ & .58 \\
Circulatory arrest (n) & 4 & 6 & .69 \\
\hline
\end{tabular}

Data are median (interquartile range).

\section{Clinical and Other Laboratory Variables}

Perioperative clinical data were collected from the patient observation charts at the time points defined above and included heart rate, arterial and central venous pressures, rectal (core) temperature, urine output, cumulative surgical drain losses, and colloid transfusion requirement. Colloid replacement was not protocol driven, but rather tailored to individual patients' metabolic and hemodynamic profiles, guided by the senior PICU clinician and surgeon.

Whole blood lactate, arterial blood gas parameters, hemoglobin concentration, platelets, total leukocyte, neutrophil, monocyte, and lymphocyte counts, blood urea nitrogen, creatinine, and coagulation parameters (international normalized ratio and activated partial thromboplastin ratio) were also measured postoperatively at the same time points.

\section{Leukocyte Subsets}

Leukocyte subsets were measured in an automated fashion by a Beckman Coulter counter (Beckman Coulter, Inc, Fullerton, Calif). We chose to use monocyte counts as an indirect marker of apoptosis for 2 reasons: (1) monocytes are known to express significant levels of $\mathrm{Fas}^{30}$ and are susceptible to FasL-induced apoptosis in vitro ${ }^{31}$ and (2) monocytes are prone to steroid-induced apoptosis via the Fas/FasL pathway in vitro. ${ }^{32,33}$ Lymphocytes do not express Fas as uniformly as monocytes (only memory CD45RO+ lymphocytes express Fas), ${ }^{34}$ and the steroid effect is dependent on the stage of the lymphocyte subtype and cell cycle. ${ }^{35}$ Neutrophils express high levels of sFas, ${ }^{30}$ but the effect of sFasL is chemotactic as well as apoptotic. ${ }^{36}$ In addition, many cytokines, including IL-6, exhibit anti-apoptotic properties toward neutrophils, ${ }^{37}$ and steroids inhibit apoptosis. ${ }^{38}$ Thus, interpretation of changes in lymphocyte and neutrophil numbers is problematic.

\section{Statistical Analysis}

Demographic data were assumed non-normal and compared by use of the nonparametric Mann-Whitney test. Sequential variables followed over time were compared by use of 2-way repeatedmeasures analysis of variance (SPSS 10.5; SPSS, Inc, Chicago, Ill). The analysis of variance model was of the general linear measures type and used marginal (type III) sums of squares because of nonorthogonality between the treatment and placebo groups. In addition, non-normal data (IL-6 and sFas only) were log transformed before analysis. Analysis of variance results are reported as group (treatment) effect, time effect, and interaction (group/time) effect. ${ }^{39}$
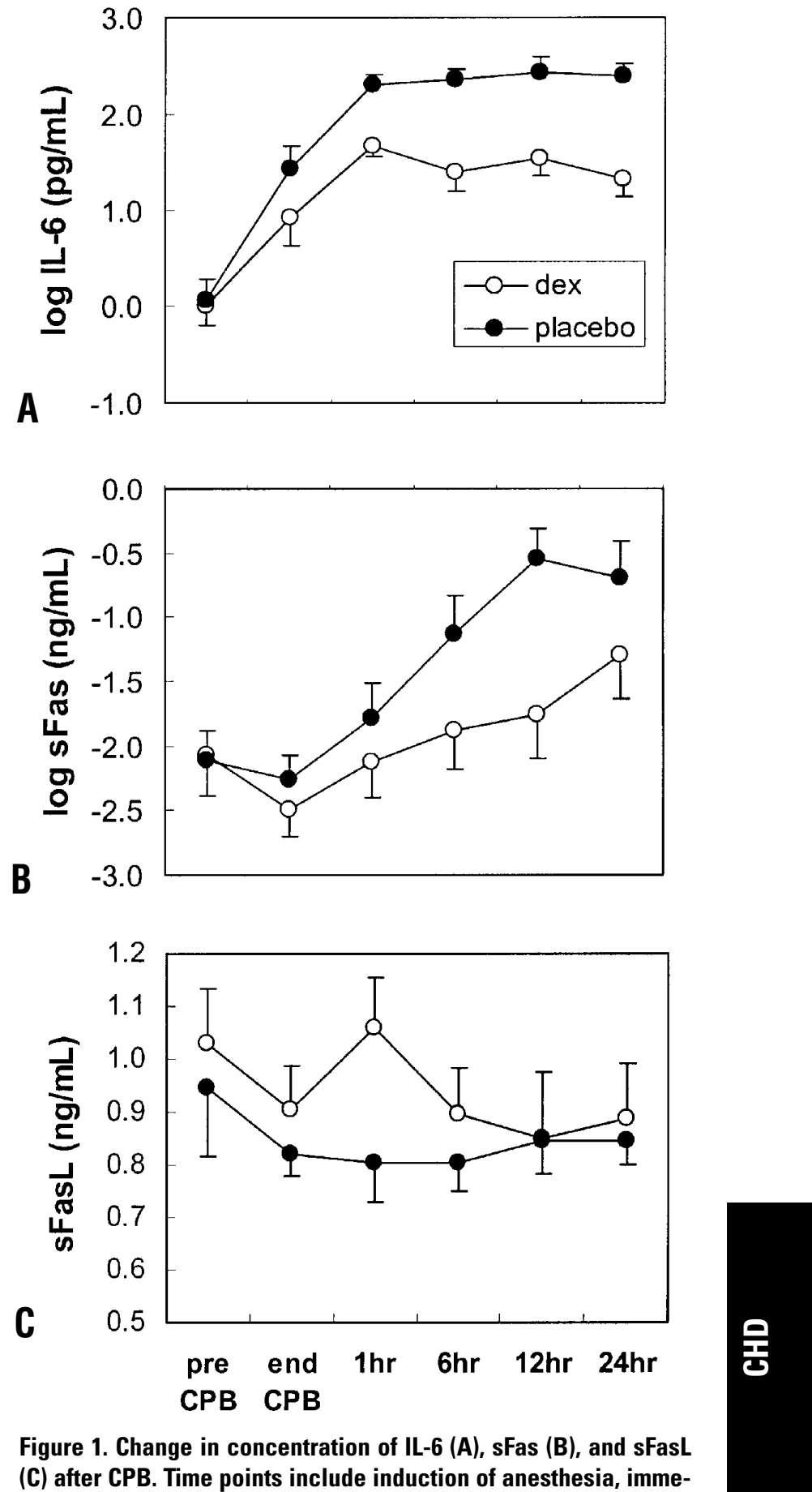
(C) after CPB. Time points include induction of anesthesia, immediately after cessation of CPB before protamine administration, and 1, 6, 12, and 24 hours after PICU admission, as defined in the "Methods" section. Data for IL-6 and sFas are log transformed; points represent mean and error bars, SEM.

A multiple regression model was used to explore whether maximum sFas, sFasL, or IL-6 levels were independently associated with duration of CPB, aortic crossclamping, circulatory arrest, or DEX administration. 
TABLE 2. Selected clinical and laboratory variables over time

\begin{tabular}{|c|c|c|c|c|c|c|c|c|c|c|}
\hline & \multirow[b]{2}{*}{ Group } & \multicolumn{6}{|c|}{ Time } & \multicolumn{3}{|c|}{ ANOVA $P$ value } \\
\hline & & Before CPB & After CPB & $1 \mathrm{~h}$ & $6 \mathrm{~h}$ & $12 \mathrm{~h}$ & $24 \mathrm{~h}$ & Group & Time & Inter. \\
\hline \multirow[t]{2}{*}{ Heart rate (beats/min) } & $\mathrm{D}$ & $124(24)$ & $147(24)$ & $148(26)$ & $139(18)$ & 137 (19) & $140(17)$ & .25 & $<.001$ & .06 \\
\hline & $\mathrm{P}$ & $118(30)$ & $158(26)$ & $158(23)$ & $159(17)$ & $159(13)$ & $138(20)$ & & & \\
\hline \multirow[t]{2}{*}{ Temp $\left({ }^{\circ} \mathrm{C}\right)$} & D & $36.7(0.4)$ & & $35.9(1.0)$ & $36.8(1.1)$ & $36.7(1.0)$ & $36.9(1.0)$ & .04 & $<.001$ & .56 \\
\hline & $P$ & $36.8(0.3)$ & & $36.4(1.4)$ & $37.5(1.1)$ & $37.4(1.0)$ & $37.3(0.5)$ & & & \\
\hline \multirow[t]{2}{*}{$\mathrm{pH}$} & D & $7.41(0.06)$ & $7.43(0.10)$ & $7.41(0.09)$ & $7.41(0.12)$ & $7.40(0.06)$ & $7.41(0.06)$ & .02 & .19 & .62 \\
\hline & $P$ & $7.40(0.07)$ & $7.39(0.12)$ & $7.32(0.15)$ & $7.40(0.07)$ & $7.35(0.06)$ & $7.36(0.05)$ & & & \\
\hline \multirow[t]{2}{*}{ Pco2 (kPa) } & D & $4.3(1.5)$ & $4.8(2.1)$ & $4.9(1.5)$ & $4.6(1.6)$ & $4.8(1.5)$ & $4.4(0.8)$ & .34 & .76 & .70 \\
\hline & $P$ & $5.1(1.0)$ & $4.5(0.8)$ & $5.2(1.2)$ & $4.6(0.9)$ & $4.9(1.1)$ & $4.9(0.7)$ & & & \\
\hline \multirow[t]{2}{*}{ Base excess } & D & $-0.3(3.7)$ & $-1.3(3.2)$ & $-1.0(2.4)$ & $-1.6(2.6)$ & $-1.2(3.6)$ & $-1.8(2.6)$ & .14 & .11 & .26 \\
\hline & $P$ & $-0.4(3.2)$ & $-2.7(4.9)$ & $-4.6(5.7)$ & $-1.6(3.4)$ & $-3.3(2.8)$ & $-2.2(3.6)$ & & & \\
\hline \multirow[t]{2}{*}{ Lactate (mmol/L) } & D & & $3.3(2.7)$ & $3.1(2.5)$ & $2.1(1.4)$ & $1.6(1.0)$ & $1.0(0.6)$ & .09 & $<.001$ & .76 \\
\hline & $P$ & & $4.0(2.4)$ & $3.7(2.1)$ & $3.2(1.7)$ & $2.4(1.8)$ & $2.3(2.4)$ & & & \\
\hline \multirow[t]{2}{*}{ INR } & D & $1.3(0.4)$ & & $1.8(0.4)$ & $1.5(0.4)$ & $1.5(0.4)$ & $1.4(0.3)$ & .09 & $<.001$ & .29 \\
\hline & $P$ & $1.3(0.4)$ & & $2.1(0.5)$ & $1.8(0.6)$ & $1.7(0.5)$ & $1.8(0.6)$ & & & \\
\hline \multirow[t]{2}{*}{ APTT } & D & $1.3(0.3)$ & & $2.1(1.0)$ & $1.6(0.6)$ & $1.6(1.0)$ & $1.3(0.3)$ & .53 & $<.001$ & .90 \\
\hline & $P$ & $1.2(0.3)$ & & $2.1(1.0)$ & $1.7(0.7)$ & $1.6(0.6)$ & $1.5(0.3)$ & & & \\
\hline
\end{tabular}

Data are mean (SD). ANOVA, Analysis of variance; inter., interaction; $D$, dexamethasone group; $P$, placebo group; INR, international normalized ratio; $A P T T$, activated partial thromboplastin time.

\section{Operation Type and Patient Demographics}

Operations were as follows: arterial switch procedure $(n=4)$, tetralogy of Fallot correction $(n=4)$, hypoplastic aortic arch repair ( $\mathrm{n}=4,3$ included a ventricular septal defect), aortic valve augmentation/replacement after prior truncus arteriosus repair $(n=3)$, Norwood stage $1(\mathrm{n}=2)$, complete atrioventricular septal defect repair $(n=2)$, complete correction of pulmonary atresia with ventricular septal defect $(n=2,1$ included unifocalization of major aortopulmonary collaterals), and Fontan, hemi-Fontan, atrial septal defect closure, repair of left atrioventricular valve, ventricular septal defect closure, and resection of subaortic stenosis $(n=1$ each). Groups were well matched in terms of age, weight, sex, and duration of $\mathrm{CPB}$, aortic crossclamping, and circulatory arrest (Table 1).

\section{Results}

IL-6, sFas, and sFasL Levels

IL-6 was undetectable in all but 4 patients (2 DEX, 2 placebo) preoperatively. All 4 were receiving infusions of alprostadil (prostaglandin $\mathrm{E}_{1}$ ) to maintain ductal patency. After CPB, IL-6 rose rapidly until 1 hour after admission to the PICU. After this time the rate of rise slowed considerably, peaking in placebo patients at 12 hours, giving median (interquartile range) levels of $424 \mathrm{pg} / \mathrm{mL}(188-584 \mathrm{pg} / \mathrm{mL})$. In contrast, peak levels in DEX patients (also at 12 hours) were considerably lower, at $65 \mathrm{pg} / \mathrm{mL}(22-77 \mathrm{pg} / \mathrm{mL})$. Although both groups showed a rise in IL-6 over time (time effect $P<.001$ ), the rise was considerably blunted in the DEX group (interaction effect $P<.01$ ). Log transformed data are shown in Figure 1, $A$.
Soluble Fas was detectable preoperatively in 9 patients (4 DEX, 5 placebo). Interestingly, only 1 of these also had detectable levels of IL-6. Overall, the pattern of change in sFas showed a similarity to IL-6 in terms of correlation $(r=$ $0.43, P<.0001$ for log-transformed values) and the attenuation with DEX (Figure 1, B). However, the rate of rise in sFas was less dramatic than that of IL-6, with peak levels also occurring at 12 hours in placebo patients, $0.42 \mathrm{ng} / \mathrm{mL}$ $(0.13-0.65 \mathrm{ng} / \mathrm{mL})$. The peak occurred later, at 24 hours, $0.21 \mathrm{ng} / \mathrm{mL}(0-0.33 \mathrm{ng} / \mathrm{mL})$, in DEX-treated patients. Like IL-6, sFas levels were elevated over time in both groups (time effect $P<.001$ ), and the response was attenuated in the DEX group (interaction effect $P<.03$ ).

Soluble FasL levels did not, however, differ between groups (group effect $P=.29$ ), nor did they change consistently over time (time $P=.25$, interaction $P=.57$ ) (Figure $1, C)$. Levels were detectable in all patients preoperatively. For placebo patients, the median preoperative and 24-hour levels were $0.844 \mathrm{ng} / \mathrm{mL}(0.703-0.984 \mathrm{ng} / \mathrm{mL})$ and 0.844 $\mathrm{ng} / \mathrm{mL}(0.750-0.922 \mathrm{ng} / \mathrm{mL})$, respectively. Corresponding levels for DEX patients were $0.875 \mathrm{ng} / \mathrm{mL}(0.813-1.188$ $\mathrm{ng} / \mathrm{mL})$ and $0.875 \mathrm{ng} / \mathrm{mL}(0.688-1.000 \mathrm{ng} / \mathrm{mL})$, respectively. Soluble FasL showed no relationship with $\log \mathrm{sFas}(r$ $=0.004, P=.97)$. It is notable that levels of both $\mathrm{sFas}$ and sFasL dropped immediately after CPB. This is likely to be due to ultrafiltration while on $\mathrm{CPB}$; certainly both molecules are small enough to be effectively filtered; however, we did not specifically measure their relative concentrations in the ultrafiltrate. 

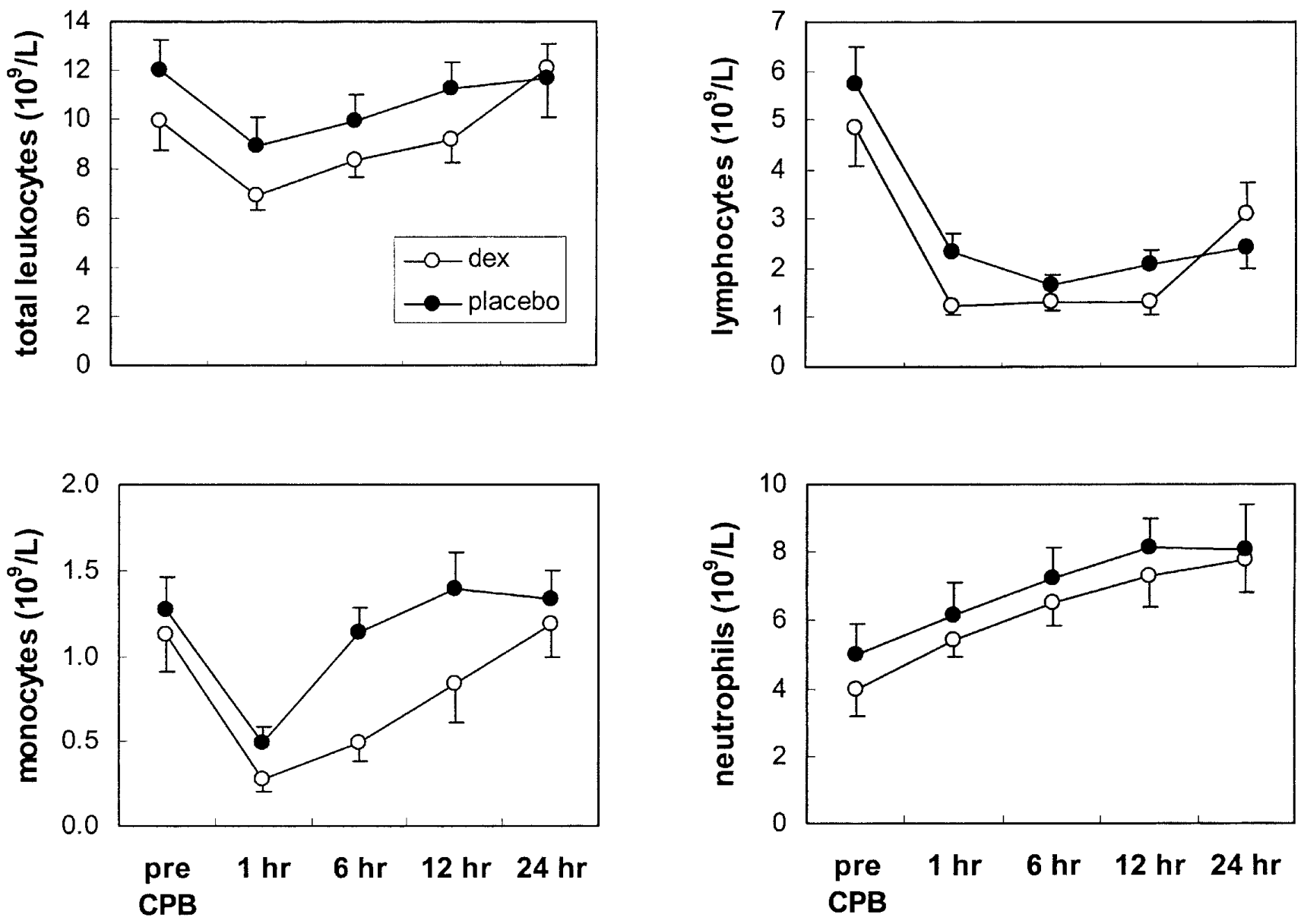

Figure 2. Change in total leukocyte, lymphocyte, monocyte, and neutrophil counts after CPB. Time points include induction of anesthesia, immediately after cessation of CPB before protamine administration, and 1, 6, 12, and 24 hours after PICU admission. Data points represent mean and error bars, SEM.

Multiple regression analysis was performed with the use of the following independent variables: age, use of DEX, duration of $\mathrm{CPB}$, duration of aortic crossclamping, and occurrence of circulatory arrest. Use of DEX was the only independent predictor for both maximum IL-6 $(P<.001)$ and sFas $(P=.04)$ levels. There was a little evidence of an independent association between duration of CPB and maximum sFas $(P=.08)$. No variable independently predicted maximum sFasL level.

\section{Markers of Systemic Inflammation}

Selected results are shown in Table 2. The change in heart rate over time (time effect $P<.001$ ) was more pronounced in placebo patients (interaction effect $P=.06$ ). This group demonstrated maximal tachycardia at 6 and 12 hours after PICU admission, coinciding with the maximum temperature difference between groups. Temperature varied over time $(P<.001)$ and was higher in the placebo group (group effect $P=.04$ ). Placebo patients had a slightly lower $\mathrm{pH}$ (group effect $P=.02$ ); this tended to be mixed in origin, as no differences were seen in $\mathrm{PCO}_{2}$ or base deficit when analyzed individually. Lactate levels fell over time in both groups. Levels were generally lower in DEX patients (group effect $P=.09$ ).

Over the first 24 hours, placebo patients had higher median (interquartile) cumulative drain losses: $25 \mathrm{~mL} / \mathrm{kg}$ (18-35 $\mathrm{mL} / \mathrm{kg})$ versus $17 \mathrm{~mL} / \mathrm{kg}(11-22 \mathrm{~mL} / \mathrm{kg})(P=.06)$. This was reflected by a greater colloid requirement to maintain hemodynamic parameters: $63 \mathrm{~mL} / \mathrm{kg}(41-131 \mathrm{~mL} / \mathrm{kg})$ versus 11 $\mathrm{mL} / \mathrm{kg}(10-64 \mathrm{~mL} / \mathrm{kg})(P=.02)$. This was not due to a difference in coagulation parameters between groups (Table 2), suggesting a higher capillary leak in placebo patients.

For all patients, the maximal logarithmic sFas value correlated both with cumulative drain loss $(r=0.37, P=.06)$ and 24-hour colloid requirement $(r=0.55, P<.01)$. There were no correlations between maximum sFasL levels and either drain loss $(r=-0.007, P=.97)$ or colloid requirement $(r=0.10, P=.62)$. 


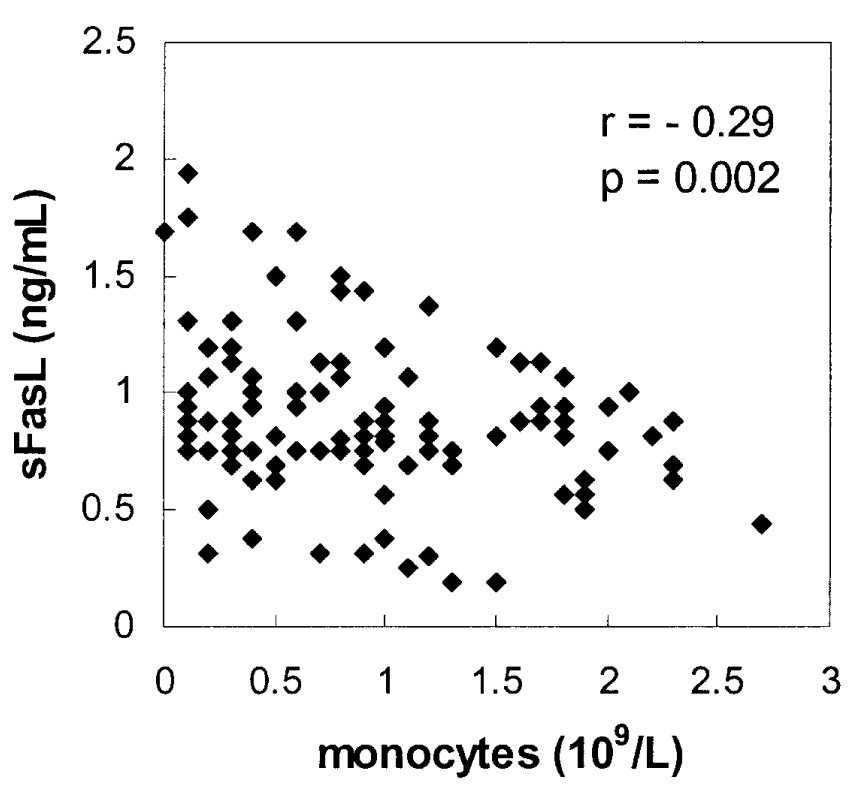

Figure 3. Scattergram showing the negative correlation between absolute monocyte count and sFasL.

There were no overall differences for mean arterial and central venous pressures, urine output, serum creatinine, or blood urea nitrogen values between groups, although creatinine and blood urea nitrogen rose in both groups over 24 hours (data not shown).

\section{Leukocyte Subsets}

Both groups demonstrated a marked fall in total white blood cell count immediately after $\mathrm{CPB}$, which was primarily due to an acquired lymphopenia and monopenia (time effects for all groups $P<.001$ ) (Figure 2). The fall in both the lymphocytes and monocytes tended to be more pronounced among DEX patients (interaction effects $P=.09$ and $P=.08$ ).

As an indirect marker for apoptosis, the absolute monocyte count correlated negatively with absolute sFasL $(r=$ $-0.29, P=.002)$ and positively with $\log$ sFas $(r=0.37, P<$ .0001) (Figure 3). However, the correlation with log sFas was spurious, because the only independent predictor of monocyte count from a multiple regression model incorporating the 2 parameters was sFasL (standardized $\beta-.59, P=.04$ ).

Lymphocyte counts correlated independently with neither sFasL (standardized $\beta-.09, P=.33$ ) nor log sFas (standardized $\beta .02, P=.84$ ). Absolute neutrophil counts rose comparably in both groups over the study period and correlated independently with $\log$ Fas (standardized $\beta=.29, P=$ .003 ) but not sFasL (standardized $\beta=-.09, P=.35$ ).

There were no differences in hemoglobin and platelets between groups (all $P>.58$ ); both fell after CPB and neither recovered completely by 24 hours (data not shown).

\section{Discussion}

We sought to examine 3 issues in this study: (1) to document the temporal profile of the release of sFas and sFasL after CPB in children; (2) to see whether steroid pretreatment altered these profiles; and (3) to see whether either of these molecules related to an indirect marker of apoptosis, namely the change in monocyte count. Results are discussed in terms of sFas, then sFasL.

\section{Soluble Fas}

Release of sFas release after CPB showed a remarkable similarity to release of IL-6, both in the pattern of rise ( $r=$ $0.43, P<.0001)$ and in the attenuation with steroid pretreatment (Figure 1). In addition, there was a trend for higher peak sFas levels with longer CPB times $(P=.08)$. Steroid pretreatment translated clinically into reduced systemic inflammatory response (heart rate, temperature, acidosis, and lactate) and capillary leak (drain losses and colloid requirement). In addition, the parameters of capillary leak correlated with maximum sFas levels. The attenuation of cytokine release and clinical inflammation after CPB with steroid pretreatment has been documented by others, ${ }^{27,28}$ but the role of sFas in this setting has not. Membrane-bound Fas is known to be a death receptor, whose role is primarily one of initiating the apoptotic cascade after ligation by membrane-bound FasL from activated T cells, natural killer cells, and macrophages. ${ }^{7}$ Membranebound Fas may also be converted to its soluble form after cleavage by specific metalloproteinases. The role of sFas has yet to be fully elucidated. Certainly the inference from this study is that sFas may be a marker of inflammation. This is consistent with other reports, in which sFas has been shown to be elevated in conditions involving an active inflammatory process. ${ }^{11-13,17-20}$

\section{Soluble Fas Ligand}

The release of sFasL after CPB was quite different from that of sFas. Soluble FasL was detectable in all patients preoperatively, compared with one third of patients (9/27) for sFas. Neither CPB nor DEX pretreatment influenced sFasL release. It is unknown whether sFasL levels equate with leukocyte membrane-bound FasL expression. If so, then high levels of sFasL should be associated with increased apoptosis. A limitation of this study is that we had no means of measuring apoptosis directly; however, we used the absolute monocyte count as an indirect marker of apoptosis. Monocytes are known to be susceptible to glucocorticoidinduced apoptosis, ${ }^{32}$ mediated via the Fas/FasL pathway. ${ }^{33}$

In our study, monocyte counts were lowest when sFasL were highest $(r=-0.29, P=.002)$. However, sFasL levels were not obviously different between steroid-treated and nontreated groups, suggesting factors other than steroids may have influenced sFasL levels. For example, the pro- 
nounced monocyte drop and slower recovery among DEXtreated patients (Figure 2) may have been exacerbated by the lower levels of sFas. It has been postulated that $\mathrm{sFas}$ may serve to block apoptosis by binding to membranebound FasL. ${ }^{40}$ Thus, the delayed monocyte recovery in the DEX group may be due to the reduction in sFas release rather than to increasing membrane-bound FasL expression and lymphocyte activation. However, it must be stressed that this remains purely speculative without an objective in vivo measure of apoptosis. Nonetheless, it is reasonable to assume that the drop in monocytes was due to apoptosis rather than extravasation, margination, or purely a CPB hemodilution or filtration effect, because neutrophil numbers did not decrease.

Regarding the potential proinflammatory role of FasL, it has been shown that membrane-bound FasL is also expressed on vascular endothelium and is shed before leukocyte extravasation. ${ }^{21}$ Shedding of membrane-bound FasL results in increased sFasL; thus, one would expect higher levels of sFasL to be seen in patients with greatest capillary leak and leukopenia. This was not the case, as sFasL correlated with neither drain loss nor colloid requirement nor did it correlate negatively with neutrophil or lymphocyte counts. In addition, sFasL did not correlate with sFas; thus, we conclude that sFasL cannot be used as an inflammatory marker in these circumstances. The reason may be that $\mathrm{sFasL}$ does not accurately reflect endothelial membrane-bound FasL expression.

\section{Limitations of the Study}

The study was nonrandomized and nonblinded. The decision to use steroids was governed by anesthetic preference and was thus governed by the day of the week the child was allocated for the operation. However, allocation was performed by a team who were unaware of the study objectives, and that is borne out by the adequate matching of variables shown in Table 1. Also, the clinicians involved in the PICU care were unaware that a link between steroid administration and clinical variables was being examined.

We were unable to perform an objective measure of apoptosis, and we did not measure the membrane-bound forms of Fas or FasL, which are known to be of far greater importance in the apoptotic cascade. Thus, any conclusions we may draw regarding apoptosis remain speculative and are limited to associations with the soluble forms of these molecules only.

It would be of interest to examine whether the change in clinical markers of inflammation translated into outcome data (eg, mortality, duration of ventilation); however, we did not attempt this analysis because the small sample size lacked statistical power. For the same reason, we cannot exclude a type 2 error in the multiple regression model examining CPBrelated factors and maximum sFas, sFasL, and IL-6 levels.
In summary, our findings suggest a possible proinflammatory role for sFas after CPB. Indeed the release of this molecule is attenuated by steroid pretreatment in a manner similar to the cytokine IL-6. This finding needs clarification in future studies. Expression of sFasL, on the other hand, showed no alteration with CPB or steroids, nor did it correlate with markers of vascular leak. However, the negative correlation with monocyte count is consistent with its role in apoptosis.

\section{References}

1. Cardiopulmonary bypass for cardiac surgery. Kirklin JK, Kirklin JW. In: Surgery of the chest, 5th edition. Philadelphia: WB Saunders; 1990. p. 1107-25.

2. Wan S, LeClerc JL, Vincent JL. Cytokine responses to cardiopulmonary bypass: lessons learned from cardiac transplantation. Ann Thorac Surg. 1997;63:269-76.

3. Gerritsen WB, Aarts LP, Morshuis WJ, Haas FJ. Indices of oxidative stress in urine of patients undergoing coronary artery bypass grafting. Eur J Chem Clin Biochem. 1997;35:737-42.

4. Cavarocchi NC, England MD, Schaff HV, Russo P, Orszulak TA, Schnell WA Jr, et al. Oxygen free radical generation during cardiopulmonary bypass: correlation with complement activation. Circulation. 1986;74(Suppl):III130-3.

5. Gottlieb RA, Burleson KO, Kloner RA, Babior BM, Engler RL. Reperfusion injury induces apoptosis in rabbit cardiomyocytes. J Clin Invest. 1994;94:1621-8.

6. Jeremias I, Kupatt C, Martin-Villalba A, Habazettl H, Schenkel J, Boekstegers P, et al. Involvement of CD95/Apo1/Fas in cell death after myocardial ischemia. Circulation. 2000;102:915-20.

7. Nagata S, Goldstein P. The Fas death factor. Science. 1995;267:1449-56.

8. Waring P, Müllbacher A. Cell death induced by the Fas/Fas ligand pathway and its role in pathology. Immunol Cell Biol. 1999;77:312-7.

9. Cascino I, Fiucci G, Papoff G, Ruberti G. Three functional soluble forms of the human apoptosis-inducing Fas molecule are produced by alternative splicing. J Immunol. 1995;154:2706-13.

10. Kayagaki N, Kawasaki A, Ebata T, Ohmoto H, Ikeda S, Inoue S, et al. Metalloproteinase-mediated release of human Fas ligand. J Exp Med. 1995;182:1777-83.

11. Toyozaki T, Hiroe M, Saito T, Iijima Y, Takano H, Hiroshima K, et al. Levels of soluble Fas in patients with myocarditis, heart failure of unknown origin, and in healthy volunteers. Am $J$ Cardiol. 1998;81:798-800.

12. Fiorina P, Astorri E, Albertini R, Secchi A, Mello A, Lanfredini M, et al. Soluble antiapoptotic molecules and immune activation in chronic heart failure and unstable angina pectoris. Clin Immunol. 2000;20: 101-6.

13. Sliwa K, Skudicky D, Bergemann A, Candy G, Puren A, Sareli P. Peripartum cardiomyopathy: analysis of clinical outcome, left ventricular function, plasma levels of cytokines and Fas/APO-1. J Am Coll Cardiol. 2000;35:701-5.

14. Toyozaki T, Hiroe M, Tanaka M, Nagata S, Ohwada H, Marumo F. Levels of soluble Fas ligand in myocarditis. Am $J$ Cardiol. 1998;82:246-8.

15. Matute-Bello G, Liles WC, Steinberg KP, Kiener PA, Mongovin S, Chi EY, et al. Soluble Fas ligand induces epithelial cell apoptosis in humans with acute lung injury (ARDS). J Immunol. 1999;163:2217-25.

16. Hashimoto S, Kobayashi A, Kooguchi K, Kitamura Y, Onodera H, Nakajima H. Upregulation of two death pathways of perforin/granzyme and FasL/Fas in septic acute respiratory distress syndrome. Am J Respir Crit Care Med. 2000;161:237-43.

17. Yasuda N, Gotoh K, Minatoguchi S, Asano K, Nishigaki K, Nomura $\mathrm{M}$, et al. An increase of soluble Fas, an inhibitor of apoptosis, associated with progression of COPD. Respir Med. 1998;92:993-9.

18. Kuwano K, Kawasaki M, Maeyama T, Hagimoto N, Nakamura N, Shirakawa K, et al. Soluble form of Fas and Fas ligand in BAL fluid 
from patients with pulmonary fibrosis and bronchiolitis obliterans organizing pneumonia. Chest. 2000;118:451-8.

19. Emmenegger U, Zehnder R, Frey U, Reimers A, Spaeth PJ, Neftel KA. Elevation of soluble Fas and soluble Fas ligand in reactive macrophage activation syndromes. Am J Hematol. 2000;64:116-9.

20. Papathanassoglou EDE, Moynihan JA, Vermillion DL, McDermott MP, Ackerman MH. Soluble Fas levels correlate with multiple organ dysfunction severity, survival and nitrate levels, but not with cellular apoptotic markers in critically ill patients. Shock. 2000;14:107-12.

21. Sata M, Walsh K. TNF $\alpha$ regulation of Fas ligand expression on the vascular endothelium modulates leukocyte extravasation. Nat Med. 1998;4:415-20.

22. Sato T, Hirasawa A, Kawabuchi Y, Nishikawa T, Wakabayashi Y. Cellular expressions and serum concentrations of Fas ligand and Fas receptor in patients with infectious mononucleosis. Int $J$ Hematol. 2000;72:329-36

23. van der Linden MW, van Lopik T, Aarden LA, Westendorp RG, Huizinga TW. Soluble CD95 concentrations are increased in patients with severe systemic lupus erythematosus, but not in their first-degree relatives. Ann Rheum Dis. 2001;60:237-41.

24. Darmochwal-Kolarz D, Leszczynska-Gorzelak B, Rolinski J, Oleszczuk J. The expression and concentrations of Fas/APO-1 (CD95) antigen in patients with severe pre-eclampsia. J Reprod Immunol. 2001;49:153-64.

25. Fuse K, Kodama M, Okura Y, Ito M, Hirono S, Kato K, et al. Predictors of disease course in patients with acute myocarditis. Circulation. 2000;102:2829-35.

26. Kayaba H, Hirokawa M, Watanabe A, Saitoh N, Changhao C, Yamada Y, et al. Serum markers of graft-versus-host disease after bone marrow transplantation. J Allergy Clin Immunol. 2000;106:S40-4.

27. Kawamura T, Inada K, Nara N, Wakusawa R, Endo S. Influence of methylprednisolone on cytokine balance during cardiac surgery. Crit Care Med. 1999;27:545-8.

28. Bronicki RA, Backer CL, Baden HP, Mavroudis C, Crawford SE, Green TP. Dexamethasone reduces the inflammatory response to cardiopulmonary bypass in children. Ann Thorac Surg. 2000;69:1490-5.

29. Butler J, Pathi VL, Paton RD, Logan RW, MacArthur KJD, Jamieson
MPG, et al. Acute-phase responses to cardiopulmonary bypass in children weighing less than 10 kilograms. Ann Thorac Surg. 1996;62:538-42.

30. Liles WC, Kiener PA, Ledbetter JA, Aruffo A, Klebanoff SJ. Differential expression of Fas (CD95) and Fas ligand on normal human phagocytes: implications for the regulation of apoptosis in neutrophils. J Exp Med. 1996;184:429-40.

31. Kiener PA, Davis PM, Starling GC, Mehlin C, Klebanoff SJ, Ledbetter JA, et al. Differential induction of apoptosis by Fas-Fas ligand interactions in human monocytes and macrophages. J Exp Med. 1997; 185:1511-6.

32. Schmidt M, Pauels H-G, Lügering N, Lügering A, Domschke W, Kucharzik T. Glucocorticoids induce apoptosis in human monocytes: potential role of IL-1 $\beta$. J Immunol. 1999;163:3484-90.

33. Schmidt M, Lügering N, Lügering A, Pauels H-G, Schulze-Osthoff K, Domschke W, et al. Role of CD95/CD95 ligand system in glucocorticoid-induced monocyte apoptosis. J Immunol. 2001;166:1344-51.

34. Miyawaki T, Uehara T, Nibu R, Tsuji T, Yachie A, Yonehara S, et al. Differential expression of apoptosis-related Fas antigen on lymphocyte subpopulations in human peripheral blood. J Immunol. 1992;149:3753-8.

35. Tuosto L, Cundari E, Montani MSG, Piccolella E. Analysis of susceptibility of mature human T-lymphocytes to dexamethasoneinduced apoptosis. Eur J Immunol. 1994;24:1061-5.

36. Ottonello L, Tortolina G, Amelotti M, Dallegri F. Soluble Fas ligand is chemotactic for human neutrophilic polymorphonuclear leukocytes. J Immunol. 1999;162:3601-6.

37. Fanning NF, Porter J, Shorten GD, Kirwan WO, Bouchier-Hayes D, Cotter TG, et al. Inhibition of neutrophil apoptosis after elective surgery. Surgery. 1999;126:527-34.

38. Cox G. Glucocorticoid treatment inhibits apoptosis in human neutrophils: separation of survival and activation outcomes. J Immunol. 1995; 154:4719-25.

39. Ludbrook J. Repeated measurements and multiple comparisons in cardiovascular research. Cardiovasc Res. 1994;28:303-11.

40. Chen J, Zhou T, Liu C, Shapiro JP, Brauer MJ, Kiefer MC, et al. Protection from Fas-mediated apoptosis by a soluble form of the Fas molecule. Science. 1994;263:1759-62. 